\title{
Randomised controlled trial of a synthetic triglyceride milk formula for preterm infants
}

\author{
A Lucas, P Quinlan, S Abrams, S Ryan, S Meah, P J Lucas
}

\begin{abstract}
Aims-To test whether use of infant formula containing synthetic structured triglycerides results in: (i) increased palmitate absorption; (ii) increased total fat absorption; (iii) reduction in calcium soap formation in the gut; and hence (iv) increased calcium absorption.

Methods-A randomised study was made of 24 infants comparing three formulas, one containing the synthetic fat Betapol with $74 \%$ of palmitate in the 2-position, which was substantially higher than in the two comparison diets $(8.4 \%$ and $28 \%)$. The hypothesised outcomes were tested using balance studies, detailed chemical analysis of stool specimens and dual calcium isotope tracers $\left({ }^{44}\right.$ calcium orally and ${ }^{46} \mathrm{cal}$ cium intravenously).

Results-Three of the four hypotheses were confirmed: use of a formula rich in 2-position palmitate (i) improved palmitate (16:0) and also (18:0) absorption; (ii) reduced the formation of insoluble calcium soaps in the stool; and (iii) improved calcium absorption, determined by the dual tracer technique from 42 (SE 3)\% to 57 (7)\%.

Conclusion-Synthetic triglycerides that mimic the stereoisometric structure of those in breast milk may have a valuable role in the design of formulas used for preterm infants in neonatal intensive care units.
\end{abstract}

(Arch Dis Child 1997;77:F178-F184)

Keywords: synthetic triglyceride; milk formula; calcium absorption; palmitate

Triglyceride provides $50 \%$ of dietary energy for infants fed breast milk. ${ }^{1}$ About a quarter of the fatty acids in breast milk triglyceride comprises the saturated fatty acid, palmitic acid. ${ }^{1}$ It has been difficult to mimic the unique stereo isomeric structure of human triglyceride in infant formulas ${ }^{12}$; this contains about $70 \%$ of its palmitic acid in the Sn-2 (middle or $\beta$ position) on the glycerol backbone. Palmitate in this position is generally not hydrolysed by pancreatic lipase and the remaining monoglyceride, which forms mixed micellae with bile salts, is well absorbed. ${ }^{34}$ Palmitic acid in the 1 and 3 positions, found predominantly in vegetable (and cows' milk) fats in infant formulas, ${ }^{2}$ is hydrolysed by pancreatic lipase and the free fatty acid may form poorly absorbed insoluble calcium-fatty acid soap complexes. ${ }^{5-11}$ This would be expected to result in reduced absorption of fatty acids and of calcium from formulas that have similar fatty acid content to breast milk. We have already suggested ${ }^{12}$ that formation of calcium soaps in the gut may in part account for the substantial difference in bowel habit between formula and breastfed infants. ${ }^{13}{ }^{14}$

With recent advances in lipid technology triglycerides can now be synthesised with palmitate in the $\mathrm{Sn}-2$ position, making it more feasible to explore whether such fats could have a favourable effect on formula fed infants.

Preterm infants fed formula may be particularly prone to fat $^{9 \text { 15-17 }}$ and calcium malabsorption, ${ }^{18}{ }^{19}$ although previous studies that have attempted to modify $\mathrm{Sn}-2$ palmitate content have produced conflicting results. ${ }^{40-22}$ We report a small but detailed randomised study in three groups of preterm infants that addresses the following hypothesis sequence: that inclusion of a high proportion of palmitate in the Sn-2 position in a low birthweight formula will (i) increase palmitate absorption and consequently, (ii) increase overall fat absorption, (iii) reduce calcium soap formation in the intestine, and therefore (iv) result in greater calcium absorption.

\section{Methods}

The subjects were preterm infants of less than $1500 \mathrm{~g}$ birthweight and less than 35 weeks of gestation, born in the Liverpool Maternity Hospital neonatal unit. Ethical approval for the study was obtained both locally and from a Medical Research Council ethics committee in Cambridge. Subjects were recruited with informed parental consent. Randomisation to diet was before 10 days of age; the principal entry criterion being that at the time of randomisation enteral feeds had started and that the mother had decided not to provide her own breast milk. Babies were excluded if they had major congenital malformations. 
Table 1 Composition of trial diets

\begin{tabular}{|c|c|c|c|}
\hline & \multirow{2}{*}{$\begin{array}{l}\text { Main diet with } \\
\text { Betapol }\end{array}$} & \multicolumn{2}{|c|}{ Comparison diets } \\
\hline & & $\operatorname{Diet} A$ & Diet $B$ \\
\hline \multicolumn{4}{|l|}{ Nutrients/100 g milk ${ }^{\star}$} \\
\hline Fat $(\mathrm{g})$ & 4.2 & 4.4 & 4.2 \\
\hline Protein $(\mathrm{g})$ & 2.0 & 2.0 & 2.1 \\
\hline Carbohydrate (g) & 8.3 & 8.2 & 8.2 \\
\hline Calcium (mg) & 76 & 77 & 77 \\
\hline Phosphorus (mg) & 41 & 42 & 42 \\
\hline Energy (kcals) & 79 & 79 & 79 \\
\hline \multicolumn{4}{|l|}{ Fatty acids:weight \%: } \\
\hline \multicolumn{4}{|l|}{ Saturated } \\
\hline 8:0 & 1.7 & 3.4 & 1.7 \\
\hline $10: 0$ & 1.3 & 2.3 & 1.2 \\
\hline $12: 0$ & 10.1 & 14.0 & 10.0 \\
\hline $14: 0$ & 4.2 & 5.3 & 4.0 \\
\hline $16: 0$ & 23.9 & 14.7 & 23.9 \\
\hline 18:0 & 3.1 & 3.8 & 3.9 \\
\hline $20: 0$ & 0.2 & 1.2 & 0.5 \\
\hline Total & 44.5 & 44.7 & 45.2 \\
\hline \multicolumn{4}{|l|}{ Monosaturated } \\
\hline $16: 1$ & 0.4 & 0.1 & 0.2 \\
\hline $18: 1$ & 36.0 & 36.6 & 35.9 \\
\hline $20: 1$ & 0.4 & 0.2 & 0.3 \\
\hline Total & 36.8 & 36.9 & 36.4 \\
\hline \multicolumn{4}{|l|}{ Polyunsaturated } \\
\hline $18: 2 \mathrm{w} 6$ & 16.3 & 16.2 & 16.4 \\
\hline $18: 3 w 3$ & 2.1 & 2.0 & 1.8 \\
\hline Total & 18.4 & 18.2 & 18.2 \\
\hline \multicolumn{4}{|c|}{ 2-position analysis weight $\%$ : } \\
\hline Total saturates & 74.8 & 31.3 & 39.6 \\
\hline Total monosaturates & 14.1 & 43.1 & 37.3 \\
\hline Total polyunsaturates & 10.4 & 25.0 & 22.0 \\
\hline $16: 0(\%$ total $)$ & 73.9 & 8.4 & 27.8 \\
\hline
\end{tabular}

$\star$ Based on actual analyses.

FORMULAS AND DIETARY MANAGEMENT

Randomisation to one of three formulas was performed using assignments in sealed envelopes, with a randomisation sequence based on permuted blocks of randomised length. The formulas, manufactured for the study by Wyeth Ayerst (USA), were coded using three numerical codes, and composition was unknown to the researcher. The codes were not broken until the study was completed. The formulas were not distinguishable on the basis of appearance or smell.

Composition of the three formulas is shown in table 1. Macronutrient composition, including total fat and calcium content, were designed to be the same in each formula (actual batch analytic values are shown in table 1 ). The proportions of total saturated, monounsaturated, and polyunsaturated fats were the same in each formula. In the main diet $23.9 \%$ of the fatty acids were palmitate (equivalent to breast milk). The fat blend included synthetic triglycerides (known as Betapol, manufactured by Loders Croklaan v.c., Wormerveer, The Netherlands), so that $73.9 \%$ of the palmitate was in the $\mathrm{Sn}-2$ position. The two comparison diets, designated $\operatorname{diet} \mathrm{A}$ and diet $\mathrm{B}$, did not contain Betapol. Diet A contained a relatively low palmitate content $(14.7 \%)$, with little of this $(8.4 \%)$ in the Sn-2 position. Diet B contained the same palmitate content as the main diet (23.9\% of fatty acids) with a fat blend that had been sourced to provide a near random distribution of palmitate positions, with $27.8 \%$ in the $S n-2$ position. The compositions of comparison diets $\mathrm{A}$ and $\mathrm{B}$ were chosen because they reflect plausible strategies that manufacturers might use in the design of fat blends for a low birthweight formula.
In diet $\mathrm{A}$ the decrease in palmitic acid content compared with that in the other two diets was balanced by an increase in all the other saturated fatty acids. The high proportion of palmitate in the $\mathrm{Sn}-2$ position in the main diet resulted in relatively lower proportions of monounsaturated and polyunsaturated fatty acids in the $\mathrm{Sn}-2$ positions than in comparison diets A and B (table 1).

After randomisation enteral feeds of the assigned formulas were increased according to feed tolerance, and parenteral nutrition, if required, decreased. Each infant was studied by conventional balance study and dual calcium isotope technique, according to protocol, at least two weeks after attainment of full enteral feeds. While the target intake of the formulas was $180 \mathrm{ml} / \mathrm{kg}$ per day, full enteral feeds was considered to be attained when an intake of over $150 \mathrm{ml} / \mathrm{kg}$ per day was achieved.

Clinical, demographic, and anthropometric data were collected until the infants were discharged from hospital. During a five day study period, a balance study was undertaken to determine total fat absorption, absorption of individual fatty acids, and excretion of soaps. During this period the dual calcium isotope procedure was performed.

COMBINED BALANCE AND DUAL ISOTOPE STUDY During the third week after attainment of full enteral feeds, a combined balance and dual tracer stable calcium isotope study ${ }^{1823}$ was undertaken for five days with a target minimum of three days (in those completing the balance-this duration was achieved in all but three cases). Overall mean balance duration was 4.0 days (table 2). The dual isotope study was conducted over 24 hours in the early part of the balance study.

Before the balance a milk feed (1/8 of 24 hour volume) was drawn up and $0.5 \mathrm{mg} / \mathrm{kg}$ of ${ }^{44} \mathrm{Ca}$ added. The feed was refrigerated and allowed to equilibrate for at least 12 hours, to be used later during the balance study.

The following morning the baby was cleaned and prepared for the balance study. Two Granuflex dressings were cut to provide a circle around the anus and the genitalia. These provided an impermeable barrier and were used to prevent excoriation and provided an effective site for fixing proprietary urine collecting bags. The stool collecting bag was inspected hourly. If a stool had been passed the bag was removed, immediately frozen, and replaced. The urine collecting bag was left in situ for the whole study, urine being siphoned under gravity into a polypropylene collecting bottle which had been washed with dilute acid, then distilled water, to remove any residual calcium. As urine was collected it was removed in aliquots and immediately frozen.

At the time of a routine venepuncture, usually on the first day of the balance, a venous cannula was inserted. Blood for routine sampling was removed from the cannula then the intravenous tracer dose of $1\left(\mathrm{~g} / \mathrm{kg}\right.$ of ${ }^{46} \mathrm{Ca}$ was injected over 5 minutes under medical supervision. Saline $(0.5 \mathrm{ml})$ was injected to flush the cannula, which was then removed. 
Table 2 Characteristics of study population: data are means (SE) or number of subjects

\begin{tabular}{|c|c|c|c|c|}
\hline & \multirow{2}{*}{$\begin{array}{l}\text { Main diet } \\
\text { including } \\
\text { Betapol }\end{array}$} & \multicolumn{3}{|c|}{ Comparison diets } \\
\hline & & $A$ & $B$ & $A+B$ \\
\hline \multicolumn{5}{|l|}{ Subjects: } \\
\hline Randomised & 10 & 10 & 10 & 20 \\
\hline Completing isotope or balance study & 8 & 9 & 7 & 16 \\
\hline Birthweight & $1260(70)$ & $1210(80)$ & $1190(90)$ & $1200(60)$ \\
\hline Gestation & $29.1(0.9)$ & $29.4(1.0)$ & $29.1(0.4)$ & $29.3(0.6)$ \\
\hline Sex: $M: F$ & $4: 4$ & $4: 5$ & $2: 5$ & $6: 10$ \\
\hline \multicolumn{5}{|l|}{ Ventilated: } \\
\hline At all & 4 & 5 & 5 & 10 \\
\hline$>7$ days & 1 & 1 & 1 & 2 \\
\hline Days to full enteral feeds & $15.9(2.3)$ & $14.2(1.6)$ & $17.7(2.7)$ & $15.8(1.5)$ \\
\hline \multicolumn{5}{|l|}{ Calcium isotope/balance study period: } \\
\hline Body weight $(\mathrm{g})$ at start & $1740(100)$ & $1800(90)$ & $1720(90)$ & $1770(60)$ \\
\hline Age (days) at start & $32.4(2.9)$ & $35.2(6.1)$ & $39.0(4.5)$ & $36.9(3.8)$ \\
\hline Duration of balance (days) & $4.0(0.5)$ & $4.3(0.2)$ & $3.2(0.7)$ & $3.9(0.4)$ \\
\hline Milk intake $\mathrm{g} / \mathrm{kg}$ per day & $185(14)$ & $185(13)$ & $189(12)$ & $187(9)$ \\
\hline${ }^{\star}$ Fat intake $\mathrm{g} / \mathrm{kg}$ per day & $7.8(0.6)$ & $8.0(0.5)$ & $8.0(0.6)$ & $8.0(0.4)$ \\
\hline${ }^{\star}$ Calcium intake $\mathrm{mg} / \mathrm{kg} /$ day & $141(11)$ & $142(10)$ & $145(9)$ & $143(7)$ \\
\hline
\end{tabular}

^ Based on actual analytic values (see table 2).

Then the milk feed tracer containing the oral ${ }^{44} \mathrm{Ca}$ was fed to the baby using a gavage feed. The syringes containing the oral and intravenous tracers were weighed before and after administration so that the doses of tracer administered could be accurately estimated.

All urine and stools were collected for 72 hours. Both stools and urine were kept frozen at $-70^{\circ} \mathrm{C}$ until they were transferred, frozen under dry ice, to Houston, Texas (urine) and Unilever laboratories in Bedford (stool). Total wet stool weight was estimated at the end of the balance study.

Regurgitations and vomits were collected on to a preweighed bib, so that such milk losses could be deducted from the milk volume administered. In practice, using gavage feeding, such events were rare. Leakage from the urine and stool collecting systems occurred occasionally and these losses were also estimated by weighing nappies before and after leakage. For the purpose of calculating net balance, these losses, which were small, were estimated to have the same composition as the collected and analysed samples. The balance method used had the advantage of low leakage rate and minimal skin excoriation.

DUAL ISOTOPE ANALYSES

A complete 24 hour urine was analysed for ${ }^{44} \mathrm{Ca} /{ }^{43} \mathrm{Ca}$ and ${ }^{46} \mathrm{Ca} /{ }^{43} \mathrm{Ca}$ and the fractional absorption of calcium calculated as the relative recovery of the oral versus the intravenous isotope in the 24 hour urine pool. The methods used were those described by Abrams et al. ${ }^{18}$ Isotopic recovery in the urine samples was determined by thermal ionisation mass spectrometry at the Children's Nutrition Research Centre in Houston, Texas. Accuracy of this technique for the isotopic ratios determined is $0.2 \%$ or less. ${ }^{18}{ }^{23}$ All isotopes were tested for sterility and pyrogenicity before administration. The analytic staff were blinded to the participants throughout the analytic and reporting period.

CHEMICAL ANALYSES OF FORMULA AND STOOLS Infant formula samples were analysed for minerals, fat, protein, carbohydrate and energy using standard Association of Official Analyti- cal Chemists (AOAC) methodology. ${ }^{24}$ Stool fatty acid soap analysis was performed as follows. Stool samples were freeze dried to remove the bulk of the water before analysis. Remaining moisture in the sample was determined using standard AOAC methodology ${ }^{24}$ and used to correct subsequent analytes to the true dry weight of the sample. Fatty acid soaps were determined essentially as described before. ${ }^{12}$ Non-soap fatty acids and neutral lipids were first extracted from the freeze dried sample $(0.5-1 \mathrm{~g})$ by refluxing for 16 hours with petroleum ether $\left(40-60^{\circ} \mathrm{C}\right.$ boiling point). This procedure does not extract fatty acid soaps. The residue was dried, mixed with $20 \mathrm{ml}$ acidified petroleum ether $(10: 1 \mathrm{v} / \mathrm{v}$ petroleum ether:acetic acid), and allowed to stand for 2 hours to solubilise fatty acid soaps by converting them to free fatty acids. The sample was then refluxed with petroleum ether for 16 hours and the acid soluble lipids quantitatively recovered. A known amount of C17:0 (heptadeconoic acid) was added as internal standard, and preparative thin layer chromatography (TLC) $(250 \mu \mathrm{m}$ silica gel plates) performed to separate the fatty acid fraction of the lipids. Plates were developed in petroleum ether/ diethyl ether/formic acid (70/30/1) and lipid bands visualised under ultraviolet light by spraying with a methanolic solution of 2,7dichlorofluorescein $(0.1 \% \mathrm{wt} / \mathrm{vol})$. The free fatty acid bands were recovered, converted to methyl esters, ${ }^{25}$ and analysed by capillary gas chromatography. ${ }^{26}$

STATISTICAL ANALYSES

The main outcomes tested were those that related to our four-stage hypothesis sequence -namely: (i) percentage of palmitate ingested absorbed from the diet; (ii) percentage of total fatty acid absorbed from the diet; (iii) percentage of dietary fat intake excreted in stools as fatty acid soaps; (iv) fractional absorption of calcium from the diet. Subsidiary outcomes included percentage absorption of other individual fatty acids. The subjects were also monitored for feed tolerance and growth rate.

Two types of statistical analysis were performed, as pre-planned, on the above outcomes. Firstly, the three randomised groups were tested for group differences in outcomes using analysis of variance. When differences were detected, any specific difference between the main diet group (receiving formula with Betapol) and either diet groups A or B was quantified using Student's $t$ test. In the second analysis groups A and B were combined (as a "low Sn-2 intake" group) and compared with the group receiving the main diet for the outcomes above, using Student's $t$ test.

Study size in this pilot was calculated to allow detection of $1.5 \mathrm{SD}$ differences in the outcomes between three groups after allowing for $20-30 \%$ post randomisation attrition of sample. Assuming that all the results lay approximately within a $5 \mathrm{SD}$ range, our sample permitted us to test our hypothesis that about $30 \%$ of the variation in the targeted outcomes was due to the randomised intervention. 
Table 3 Principal results (i) absorption of palmitate (16:0) (ii) total fatty acid absorption (iii) proportion of milk fat intake excreted as soaps (iv) fractional absorption of calcium (by dual isotope techniquet

\begin{tabular}{|c|c|c|c|c|}
\hline & \multirow{2}{*}{$\begin{array}{l}\text { Main diet } \\
\text { including } \\
\text { Betapol }\end{array}$} & \multicolumn{3}{|l|}{ Comparison diets } \\
\hline & & $A$ & $B$ & $A+B$ \\
\hline \multicolumn{5}{|l|}{ Balance study: } \\
\hline $\mathrm{n}=$ & 7 & 9 & 6 & 15 \\
\hline Percentage palmitate absorbed $(16: 0)$ & $91.4(2.1)$ & $79.3(3.2)[-21.0,-3.3]^{\star \star}$ & $78.9(3.1)[-20.6,-4.4]^{\star \star \star}$ & $79.1(2.2)[-19.8,-4.8]^{\star \star \star}$ \\
\hline Percentage total fatty acid absorbed & $93.5(1.8)$ & $92.0(1.3)[-6.2,3.2]$ & $88.7(2.5)[-11.6,1.9]$ & $90.6(1.3)[-7.6,1.9]$ \\
\hline Percentage milk fat intake excreted as fatty acid soaps & $3.3(0.7)$ & $5.6(1.1)[-0.6,5.2]$ & $7.2(0.8)[1.6,6.3]^{\star \star \star}$ & $6.2(0.7)[0.5,5.4]^{\star \star}$ \\
\hline \multicolumn{5}{|l|}{ Calcium isotope study: } \\
\hline $\mathrm{n}=$ & 7 & 8 & 7 & 15 \\
\hline Fractional absorption of calcium & $57.0(7.2)$ & $43.9([-30.1,3.9]$ & $40.0(4.5)[-35.4,1.4]$ & $42.1(2.9)[-28.3,-1.6]$ \\
\hline
\end{tabular}

$\star \star \mathrm{p}<0.03 ;{ }^{\star \star \star} \mathrm{p}<0.01$.

† Data as means (SE). Data in square brackets are $95 \%$ confidence interval for difference from main diet.

In view of the chance uneven sex ratio in diet group B, further regression analysis was used to explore whether group difference identified could be attributed to sex distribution.

\section{Results}

Table 2 shows the characteristics of the study population. Thirty subjects were randomised-10 in each diet group. Completed studies (balance, isotope study, or both) were obtained in $24(80 \%)$ of these subjects; 21 $(70 \%)$ had successful balances; and $21(70 \%)$ had successful isotope studies. Failure to obtain either balance or isotope study data or both was due principally to the subject failing to meet the study criterion (at least two weeks of full feeds on the trial diet) before hospital discharge or transfer: a few subjects were also lost due to technical failure of the procedurefor example, due to substantial balance losses from leakages or failure to achieve continuous intravenous calcium isotope infusion.

The data in table 2 refer only to those $80 \%$ of subjects studied by balance or isotope technique. The groups had similar mean birthweights, gestation, and requirement for ventilatory assistance. By chance, there were more girls than boys in diet group B, and this is accounted for in our analyses. The three groups attained full enteral feeds at a similar time, with group means near the start of the third week. At the start of the balance and isotope study, mean age and body weight was similar between groups. Milk volume intake, total fat, and calcium intakes were also similar between groups. The recorded milk volume intakes in each subject, together with actual analytic data on the batches of formula fed in the study, were used to calculate individual intakes of total fat, fatty acids, and calcium.

Table 3 shows the results of the four key outcomes relative to our hypothesis sequence.

(i) The proportion of palmitic acid (16:0) absorbed from the formula was greatest in those fed the main diet (containing Betapol) and was significantly less in subjects receiving diets A (despite its lower palmitate content) or $\mathrm{B}$, both of which had less palmitate in the $\mathrm{Sn}-2$ position than in the main diet. Differences between the three diet groups were initially identified using analysis of variance $(\mathrm{F}=5.5$, $\mathrm{p}=0.013)$. When the main diet group was compared with diets A plus B combined, overall palmitate absorption was only 79.1 (SE
$2.2) \%$ in the latter, compared with $91.4(2.1) \%$ in the main diet group $(\mathrm{p}<0.01)$.

(ii) We were unable to confirm that this reduction in palmitic acid absorption was reflected in an overall reduction in total fatty acids, although the fatty acid absorption in diet groups A and B was lower, particularly in diet group B, where mean total fatty acid absorption was $88.7(2.5) \%$ compared with 93.5 (1.8) $\%$ in those fed the main diet.

(iii) As hypothesised, the feed groups differed significantly (by analysis of variance) in the proportion of fat intake excreted in the stools as calcium soaps $(p<0.02)$, accounted for by the significantly higher value in group $B$, which was over twice that in the main diet group $(\mathrm{p}<0.01)$. A substantial and significant increase in the proportion of ingested fat that was excreted as soaps was seen also for diet groups $\mathrm{A}$ and $\mathrm{B}$ combined, compared with that for the main diet group $(\mathrm{p}<0.03)$.

(iv) The estimated mean fraction of dietary calcium absorbed from the diet was lower in diet groups A (43.9\% absorption) and B (40.0\% absorption) than in the main diet group (57.0\% absorption). These group differences did not reach significance individually. However, when groups A and B were combined, the 42.1 (SE 2.9)\% calcium absorption was significantly lower than the $57.0(7.2) \%$ absorption in the main diet group $(p<0.03)$.

Table 4 shows a subsidiary analysis of the absorption of individual fatty acids. Apart from the lower palmitate absorption in diet groups $\mathrm{A}$ and $B$, absorption of $C 18: 0$ was also reduced in diet group $B(p<0.05)$ and $\operatorname{diet}$ groups $A$ and $B$ combined $(p<0.05)$ compared with that in the

\section{Key messages}

- Synthetic structured triglycerides can provide palmitic acid predominantly in the 2-position, like breast milk, rather than predominantly in the 1 and 3 positions as in modern formulas.

- Use of such fats in formula for preterm infants can improve absorption of saturated fats, palmitate, and stearate.

- Improved saturated fat absorption reduces calcium soap formation in the intestine.

- In turn, this improves calcium absorption, determined by dual calcium isotope kinetics. 
Table 4 Absorption of individual fatty acids: data are percentage absorption values (SE) with 95\% confidecne intervals for difference between diet $A$ or $B$ and main diet

\begin{tabular}{|c|c|c|c|c|}
\hline & \multirow{2}{*}{$\begin{array}{l}\text { Main diet (Betapol) } \\
(n=7)\end{array}$} & \multicolumn{3}{|l|}{ Comparison diets } \\
\hline & & $A(n=9)$ & $B(n=6)$ & $A+B(n=15)$ \\
\hline \multicolumn{5}{|l|}{ Saturates: } \\
\hline C12:0 & $97.4(1.1)$ & $97.3(0.5)[-2.6,2.4]$ & $96.7(0.9)[-4.0,2.4]$ & $97.1(0.5)[-2.5,1.7]$ \\
\hline C14:0 & $93.6(2.4)$ & $90.7(1.6)[-8.7,3.0]$ & $88.5(2.1)[-12.2,2.0]$ & $89.8(1.2)[-8.8,1.3]$ \\
\hline C16:0 & $91.4(2.1)$ & $79.3(3.2)[-21.0,-3.3]^{\star \star}$ & 78.9 (3.1) $[-20.6,-4.4]^{\star}$ & $79.1(2.2)[-19.8,-4.8]^{\star \star \star}$ \\
\hline C18:0 & $81.0(4.5)$ & $69.0(4.3)[-25.5,1.6]$ & $66.2(4.2)[-28.6,-1.0]^{\star}$ & $67.9(3.0)[-24.3,-1.8]^{\star}$ \\
\hline $\mathrm{C} 20: 0$ & $66.2(9.9)$ & $51.5(8.4)[-42.4,13.1]$ & $49.5(5.5)[-43.0,9.6]$ & $50.7(5.3)[-37.0,6.0]$ \\
\hline \multicolumn{5}{|c|}{ Monosaturates: } \\
\hline C18:1 & $94.6(1.7)$ & $95.9(0.8)[-2.5,5.1]$ & $93.9(3.0)[-8.0,6.5]$ & $95.1(1.2)[-4.0,5.0]$ \\
\hline \multicolumn{5}{|c|}{ Polyunsaturates: } \\
\hline C18:2 & $95.2(1.8)$ & $96.9(1.0)[-2.6,6.0]$ & $95.0(2.3)[-6.6,6.3]$ & $96.1(1.1)[-3.3,5.2]$ \\
\hline $\mathrm{C} 18: 3$ & $96.3(1.5)$ & $97.7(0.9)[-2.4,5.0]$ & $96.0(1.8)[-5.5,4.9]$ & $97.0(0.9)[-2.8,4.2]$ \\
\hline
\end{tabular}

main diet group. Absorption of C14:0, and in particular, C20:0 in the non-Betapol containing diets ( $\mathrm{A}$ and $\mathrm{B}$ ) was lower, although this did not reach the $5 \%$ significance level (detection of differences of these magnitudes would have required a larger trial). Mono- and polyunsaturated fatty acids were equally well absorbed in all diet groups.

No differences between diet groups were found for steady state gains in weight, length, or head circumference during the whole period on the assigned diets.

In view of the chance excess of female subjects in group B, the possible impact of sex on our findings was explored. The infant's sex was found to be unrelated to palmitic acid absorption, other individual or total fatty acid absorption, soap excretion or fractional calcium absorption. As expected, therefore, in view of these negative associations, adjusting for the infants' sex did not change the magnitude or significance of any of the outcome findings in tables 3 and 4 .

\section{Discussion}

In this small randomised trial of intensively studied premature infants fed one of three preterm formulas, we have shown that inclusion of synthetic triglycerides with palmitate predominantly in the Sn-2 position had a significant impact on fatty acid absorption, reduced calcium soap formation in the gut, and increased calcium absorption from the diet. These findings suggest a potentially important role for such synthetic lipids in formulas intended for use in neonatal intensive care.

Our first hypothesis was that an increase in the proportion of palmitate in the Sn-2 position would improve palmitate absorption. ${ }^{40}$ There has been longstanding interest in this question but conflicting results. ${ }^{20-22}$ Only recently, however, has it been possible to study this issue using synthetic triglycerides. A small crossover study on preterm infants had shown that during one week on a Betapol formula, absorption of palmitate was increased. ${ }^{27}$ Our study allowed us to test this hypothesis in a longer term, non-crossover study in which the formulas were fed throughout the period of neonatal intensive care, as would occur in practice. The most comparable contrasting diet was diet B, with the same composition as the main diet containing Betapol, except that $28 \%$ rather than $74 \%$ of the palmitate was in the Sn-2 position. The $28 \%$ palmitate in the $\mathrm{Sn}-2$ position in diet $\mathrm{B}$, while substantially lower than that in the main diet, is nevertheless a high value for vegetable fat requiring carefully sourced oils, as might be used in a modern formula. Both these diets had palmitate contents of $24 \%$ of total fatty acids, close to that in breast milk. ${ }^{1}$ However, we also tested a further comparison diet (diet A) which deployed a strategy, used by some formula manufacturers, of reducing the palmitate content - in this case to $15 \%$, to improve fat absorption. Diet A had only $8.4 \%$ of palmitate in the Sn-2 position, typical of vegetable fats. Diets A and B provided a similar proportion of palmitate in the 1 and 3 positions in relation to total fatty acid intake: $14 \%$ and $17 \%$, respectively, compared with only $6 \%$ in the main diet. Despite the small study sample, palmitate absorption was significantly reduced from both formulas A and B compared individually with that in the Betapol formula. The significance level was high so that even if correction for multiple comparisons was made (there were four, albeit interdependent, outcomes) the observed difference would be unlikely to have been due to chance. Indeed, there was little overlap in palmitate absorption values among the groups: only five of 15 subjects studied on $\operatorname{diet} \mathrm{A}$ or $\mathrm{B}$ had palmitate absorption values above the lowest value seen with the Betapol diet and none of these five subjects had values as high as the mean value in the Betapol group.

We hypothesised (ii) that as saturated fatty acids of 16 carbons length (palmitate) and over are generally relatively poorly absorbed (table 4), relating to their tendency to form insoluble soaps, an increase in palmitate absorption might result in an overall increase in fat absorption. This could not be proved here. Subjects fed the Betapol formulas had a total fatty acid excretion of only $6.5 \%$ of intake. On diet $\mathrm{B}$, this value was $11.3 \%$ (around $75 \%$ higher), but a slightly larger study would have been needed to detect this level of difference with adequate power and significance. Indeed, in a contemporaneous study on 27 full term infants, Carnielli and coworkers found that a formula containing $47 \%$ of palmitate in the Sn-2 position significantly increased total fat absorption compared with that in formulas with lower contents of Sn-2 palmitate. ${ }^{28}$ Certainly Betapol could be expected to have a substantial effect on saturated fatty acid 
absorption; we found both 16:0 and 18:0 absorption were increased with a (nonsignificant) increase in absorption of $14: 0^{27}$ and of 20:0. The higher 18:0 absorption probably related to the higher proportion of 18:0 in the $\mathrm{Sn}-2$ position in the Betapol formula (28\%) compared with the other formulas (only $11 \%$ for formula B).

We hypothesised that the reduction in saturated fat absorption would result in fatty acid soap formation (iii), ${ }^{5-11}$ and our data provide compelling evidence for this. Calcium soap excretion, as a proportion of fatty acids ingested, was around half the value with the Betapol diet than with diets A or B. We and others have already observed several small preterm infants who developed intestinal obstruction $^{810-12}$ using preterm formulas with palmitate contents similar to breast milk, yet mainly in the $\mathrm{Sn}-1$ or -3 positions. We have suggested that the obstruction was due to inspissated fatty acid soaps, and recently we reported a case ${ }^{12}$ where this was confirmed by analysis of inspissated material at laparotomy undertaken for disempaction of the bowel. Though uncommon, this is a potentially life threatening complication of current low birthweight formulas. In the USA this complication is rarely seen, possibly because of the very low palmitate contents (often close to $5 \%$ ) used in preterm formulas, but such formulas may contain non-physiologically high proportions of other fatty acids, for instance those of medium chain length (MCT). Clearly, the use of synthetic triglycerides with saturated fats in the Sn-2 position may allow more "physiological" palmitate contents in formulas to be absorbed well, with less intraluminal soap formation.

Our fourth hypothesis was that fatty acid soap formation would bind calcium in the gut $^{5} 7911$ and therefore reduce calcium absorption. Using a dual calcium isotope method, ${ }^{18}$ we found evidence to support this view, and our findings are consistent with those of others using short term balances. ${ }^{26}$ For diet groups A and $\mathrm{B}$ combined, calcium absorption, at only $42 \%$, was substantially lower than the $57 \%$ absorption seen in the group fed formula containing Betapol. Interestingly, this average fractional absorption of calcium $(57.0 \%)$ was very similar to that found by Abrams (unpublished) of 53.4 (SE:3.7)\% in a group of eight infants fed human milk fortified with a commercial human milk fortifier. We recognise that calcium retention near to that in utero has been achieved in well preterm infants using formulas with calcium contents substantially higher than those in the formulas in this study. Nevertheless, calcium absorption and retention clearly remain problems in preterm infants. ${ }^{18} 19$ These infants often have periods of illness when adequate calcium nutrition is difficult to achieve and they are frequently discharged home with bones that are undermineralised $^{19}$ and may remain so for months.

Our study generally confirmed our initial hypothesis sequence, but a larger trial will be needed to test whether there are associated clinical benefits-for instance, improved growth and energy balance due to greater absorption of fatty acids and improved bone mineralisation resulting from greater dietary calcium absorption.

A larger trial is also required to assess safety aspects, although the purpose of using lipids with saturated fats in the Sn-2 position in infant formulas is to achieve the stereo isomeric structure of triglycerides found in breast milk, which is widely accepted for use in feeding preterm infants. One concern previously raised is that the rearrangement of fatty acids occupying the $\mathrm{Sn}-2$ position could reduce essential fatty acid (18:2n6) absorption. ${ }^{27}$ Reassuringly, we did not confirm this - absorption of linoleic $(18: 2 n 6)$ and linoleic $(18: 3 n 3)$ acids were very similar in all three feed groups. We did not find significant differences in growth or in feed tolerance, but our study was not large enough to explore these aspects sufficiently.

In conclusion, our study provides evidence that attention to the stereo isomeric structure of triglycerides in preterm formulas may have substantial effects on fatty acid and calcium absorption and handling in the gut. These effects could be of considerable clinical and biological relevance and should be explored further.

We gratefully acknowledge the kind help of the nursing staff at the Regional Neonatal Unit, Liverpool, the support of the Medical Research Council, and Wyeth Ayerst for manufacturing and supplying the formulas.

1 Jensen RG. Lipids in human milk composition and fat soluble vitamins. In: Lebenthal E, ed. Textbook of gastroenterology and nutrition in infancy. 2nd edn. New York: Raven Press, 1989:157-208

2 Breckenridge WC. Stereospecific analysis of tricylglycerols. In: Kuksis A, ed. Handbook of lipid research 1 - fatty acids and glycerides. New York: Plenum Press, 1978:197-232.

3 Thomson AB, Keelan M, Garg ML. Clandinin MT. Intestinal aspects of lipid absorption: in review. Can $\mathcal{F}$ Physiol Pharmacol 1989;67:179-91.

4 Filer LJ, Mattson FH, Foman SJ. Triglyceride configuration and fat absorption by the human infant. $\mathcal{f}$ Nutr 1969;99:293-8.

5 Bosworth W, Bowditch HI, Giblin LA. Studies of infant feeding X. Calcium in its relation to the absorption of fatty acids. Am F Dis Child 1918;15:397-407.

6 Hanna FM, Navarette DA, Hsu FA. Calcium-fatty acid absorption in term infants fed human milk and prepared formulas simulating human milk. Pediatrics 1970;45:21624

7 Watkins JB, Bliss CM, Donaldson RM, Lester R. Characterisation of newborn faecal lipid. Pediatrics 1974;53:51115.

8 Lewis CT, Dickson JAS, Swain VAJ. Milk bolus obstruction in the neonate. Arch Dis Child 1977;52:68-71.

9 Chappell JE, Clandinin MT, Kearny-Volpe C, Reichman B, Swyer PW. Fatty acid balance studies in premature infants fed human milk or formula: effect of calcium supplementation. F Pediatr 1986;108:439-47.

10 Koletzko B, Tangermann R, von Kries R, Stannigel H, Willberg B, Radde I, Schmidt E. Intestinal milk bolus obstruction in formula-fed premature infants given high doses of calcium. I Pediatr Gastroenterol Nutr 1988;7:548-53.

11 Wales JKH, Milford D, Okorie NM. Milk bolus obstruction secondary to the introduction of premature baby milk formula: an old syndrome re-emerging in a new population. Eur $\mathcal{F}$ Pediatr 1989;148:676-8.

12 Quinlan PT, Lockton S, Irwin J, Lucas AL. The relationship between stool hardness and stool composition in breast and formula-fed infants. f Ped Gastroenterol Nutr and formula-fed

13 Weaver LT, Ewing G, Taylor LC. The bowel habit of milkfed infants. F Pediatr Gastroenterol Nutr 1988;7:568-71.

14 Weaver LT, Lucas A. Development of bowel habit in preterm infants. Arch Dis Child 1993; 68:317-20.

15 Jarvenpaa L. Feeding the low birthweight infant I.V. Fat absorption as a function of diet and duodenal bile acids. Pediatrics 1983;72:684-9.

16 Alemi B, Hamosh M, Scanlon JW, Salzman-Mann C, Hamosh P. Fat digestion in very low birthweight infants: effect of administration of human milk to low birthweight formula. Pediatrics 1981;68:484-9.

17 Signer E, Murphy GM, Edkins S, Anderson CM. Role of bile salts in fat malabsorption of premature infants. Arch Dis Child 1974;49:174-80. 
18 Abrams SA, Schanler RJ, Yergey AL, Vieira NE, Bronner F. Compartmental analyses of calcium metabolism in very

9 Koo WK, Tsang RC. Calcium, magnesium, phosphorus and Vitamin D in nutritional needs of the preterm infant. In: Tsang RC, Lucas A, Uauy R, Zlotkin S, eds. Caduceus Medical Publishers Inc, 1993:135-56.

20 Tomarelli RM, Meyer BJ, Weaber JR, Bernhart FW. Effect of positional distribution on the absorption of the fatty acids of human milk and infant formulas. $\mathcal{F}$ Nut 1968;95:583-90.

21 Verkade HJ, van Asselt WA, Vonk RJ, et al. Fat absorption in premature infants: the effect of lard and antibiotics. Eur $\mathcal{F}$ Pediatr 1989;149:126-9.

22 Quinlan P, Moore S. Modification of triglycerides by lipases: process technology and its application to the production of nutritionally improved fats. Informatics 1993;4:580-5.

23 Stalhos TH, Shulman RJ, Schanler RJ, Abrams SA. Effect of carbohydrates on calcium absorption in premature infants. carbohydrates on calcium abso
24 AOAC. Official Methods of Analysis, 15th edn. Helrich K, ed. Virginia: AOAC Inc: 1990: 27, 42, 69, 70 and 88.

25 Hammond EW. Packed column chromatography and its application to analysis of fats and oils. In: Hamilton RJ, Rossell JB, eds. Analysis of oils and fats. New York: Elsevier Applied Sciences,1986:113-35.

26 Ackman RG. Capillary gas-liquid chromatography. In: Hamilton RJ, Rossell JB, eds. Analysis of oils and fats. New York: Elsevier Applied Sciences, 1986:137-206.

27 Carnielli VP, Luijendijk IHT, van Goudoever JB, et al. Feeding premature newborn infants palmitic acid in amounts and stereoisomeric position similar to that of human milk: effects on fat and mineral balance. Am $f$ Clin Nutr effects on fat and

28 Carnielli VP, Luijendijk IHT, van Goudoever JB, et al. Structural position and amount of palmitic acid in infant formulas: effects on fat, fatty acid and mineral balance. $\mathcal{F}$ Pediatr Gastroent Nutr 1996;23:553-60. 